\title{
An Overview of Diagnosis Neonatal Sepsis with Antimicrobial Management
}

\section{Edwin Dias}

Professor and HOD, Department of Pediatrics, Srinivas Medical College \& Research Centre, and Adjunct Professor, Srinivas University, Mangalore, India

E-Mail: dredwindias@gmail.com

Area/Section: Health Sciences.

Type of the Paper: Review Paper.

Type of Review: Peer Reviewed as per $|\mathrm{C}| \mathrm{O}|\mathrm{P}| \mathrm{E} \mid$ guidance.

Indexed in: OpenAIRE.

DOI: http://doi.org/10.5281/zenodo.3766836.

Google Scholar Citation: IJHSP

\section{How to Cite this Paper:}

Dias, Edwin. (2020). An Overview of Diagnosis Neonatal Sepsis with Antimicrobial Management. International Journal of Health Sciences and Pharmacy (IJHSP), 4(1), 1-12. DOI: $\underline{\text { http://doi.org/10.5281/zenodo.3766836. }}$

International Journal of Health Sciences and Pharmacy (IJHSP)

A Refereed International Journal of Srinivas University, India.

(C) With Author.

\section{(@) $(1) \Theta$}

This work is licensed under a Creative Commons Attribution-Non Commercial 4.0 International License subject to proper citation to the publication source of the work.

Disclaimer: The scholarly papers as reviewed and published by the Srinivas Publications (S.P.), India are the views and opinions of their respective authors and are not the views or opinions of the SP. The SP disclaims of any harm or loss caused due to the published content to any party. 


\title{
An Overview of Diagnosis Neonatal Sepsis with Antimicrobial Management
}

\author{
Edwin Dias \\ Professor and HOD, Department of Pediatrics, Srinivas Medical College \& Research Centre, \\ and Adjunct Professor, Srinivas University, Mangalore, India \\ E-Mail: dredwindias@gmail.com
}

\begin{abstract}
Neonatal sepsis is one of the most prevalent major health problems, affecting an estimate of around thirty million newbornseach year throughout the world. The onset of sepsis within the first fourty-eight hours after birth is associated with prenatal and perinatal predisposing factors. The on set of sepsis between fourty-eight and seventy-two hours of life usually indicatesnosocomially acquired infections. Klebsiella Pneumonia is the leading pathogenic organism causing neonatal sepsis in Asian countries, and the most important etiological factor for neonatal sepsisis found to be low birth weight. Sepsis score is a useful method for early and rapid diagnosis of neonatal sepsis. Antibiotics are given to most neonates suspected to be infected. Ampicillin and gentamicin are the first line treatment. The occurrence of neonatal sepsis can be brought down by practising clean and safe delivery, early \& exclusive breast feeding, strict postnatal cleanliness which should be followed by adequate hand-washing and aseptic methods. Neonatal sepsis is the third leading cause of neonatal mortality and a major public health problem. Despite major advances in neonatal medical care, the frequent presence of non-infectious conditions resembling sepsis pose a challenge to the diagnosis of neonatal sepsis, especially seen in preterm infants. Another factor complicating the diagnostic procedure is the absence of optimal diagnostic tests. Neonatal sepsis is among the leading high-risk diseases that infect newborns, especially preterm infants, warranting an aggressive line of treatment. Clinical practitioners are compelled to use broad spectrum antibiotics to neonates with high risk factors and/or signs of suspected infection. But the use of empirical antibiotic coverage and also their prolonged use contribute to the rising incidence of resistance amongst microbial strains.Apart from the high occurrence rate and mortality rate of sepsis in preterm infants, its long-term consequences also include adverse effects on growth and development. In our review, we touch upon the most common doubts and challenges faced during the diagnosis and management of neonatal sepsis. [1].
\end{abstract}

Keywords: Neonatal sepsis, Antibiotics, Neonatal, Diagnostic tests.

\section{INTRODUCTION :}

Neonatal sepsis also called as sepsis neonatorum occurs when pathogenic bacteria gains access into the blood stream [1].In this review, following headings will be discussed:

\subsection{Epidemiology:}

In the recent years, a considerable drop in childhood mortality has been achieved worldwide. However, neonatal mortality still continues to contribute to this largely, representing $40 \%$ of all childhood mortality. An alarming number of neonatal deaths are reported every year - roughly 2.6 million/year; 3/4ths of which were reported to occur within their first week of life. Another striking trend noticed is that majority of these deaths occur in low- and middle-income countries. This trend is a direct reflection of the lack of an effective surveillance system in these developing countries, as a result of which a high number of newborns in those countries die at home even before theregistration. 
Neonatal sepsis has been reported to be the forerunner of causes of neonatal death, closely followed by pre-maturity \& intra-partum complications (such as birth asphyxia). This accounts for $13 \%$ of all neonatal mortality, and $42 \%$ of deaths to occur in the first week after birth. As a result, neonatal sepsis is most probably under-reported in these countries, suggesting that its effect on mortality can be even higher.

Newborns, especially pre-term babies, are more prone to infections than children of any other age group. Innate immunity of babies is affected by impaired cytokine production, decrease in expression of adhesion molecules in neutrophils \& also due to a decreased response to chemotactic factors. Transplacental passage of antibodies starts during the second trimester and achieves its maximal speed during the $3^{\text {rd }}$ trimester, resulting in most preterm newborns having significantly decreased humoral responses[2].

\subsection{Common Causes of Neonatal Sepsis:}

Neonatal sepsis can be divided into early-onset (if symptoms start before seventy-two hours of life) and late-onset (if symptoms start afterward). Various cut-off points have been used, from fourty-eight hours to seven days. But most epidemiological studies use the seventy-two hours.

Early-onset sepsis occurs due to maternally transmitted pathogens[3]. Chorioamnionitis, maternal intra-partum fever, prematurity, prolonged rupture of membranes \& inadequate intra-partum antibiotic prophylaxis increases its risk. Late-onset sepsis occurs due to nosocomial infections and is more common in preterm babies and in new-borns with prolonged hospitalisations, use of central lines, para-enteral feeding \& mechanical ventilation. The occurrence of early-onset neonatal sepsis in developed countries is $0.9-1.5$ per 1000 live births. One of the most common cause of early-onset sepsis is Group B Streptococcus (GBS), isolated in half of cases, followed by Escherichia coli, isolated in one-fourth of cases[4]. The remaining cases of early-onset sepsis are caused by Staphylococcus aureus, Coagulase-negative Staphylococcus (CoNS), Listeria monocytogenes and other gramnegative bacteria. In cases of very-low-birthweight newborns (<1500 g), E. coli is more common than GBS. Late-onset sepsis occurs mainly in very-low-birth-weight infants. Its occurrence in developed countries is 3-3.7 per 1000 live births. The main pathogenic organism is CoNS, responsible for half of cases. Other important pathogenic agents responsible are E. coli, Klebsiellasp and Candida sp. Together they result in one-third of episodes. S. Aureus causes less common cases of late-onset sepsis followed by Enterococcus sp and Pseudomonas aeruginosa. Late-onset pathogens are more resistant to antibiotics than early-onset pathogens. One of the major obstacles in the treatment of neonatal sepsis is getting a precise diagnosis. Unlike older patients, newborns have more indistinct clinical presentations, and multiple clinical conditions closely resemble neonatal sepsis. Auxiliary tests are of limited value and are difficult to interpret due to low sensitivity \& altering normal ranges during the neonatal period. Blood cultures also lack in sensitivity due to specific characteristics of the neonatal group. This results in a need for combination of findings, necessary to provide an accurate diagnosis of neonatal sepsis. Deciding on how to incorporate these tests is a subject of great controversy[5].

\section{OBJECTIVES :}

This review deals mainly with an in-depth review of Diagnostic tools and antibiotics used to manage neonatal sepsis which is a challenging problem all over the world.

\section{LITERATURE REVIEW :}

\subsection{Diagnostic tools of Neonatal sepsis}

The clinical signs of neonatal sepsis are nonspecific. The National Institute of Child Health and Human Development (NICHD) Neonatal Research Network found, in their studies that increasing apnea, feeding intolerance, abdominal distension or hemepositives tools, increase in respiratory support, lethargy, and hypotonia were the most common presenting signs of late onset sepsis (LOS). None of these were found to have a high predictive accuracy. However, many neonatologists practicing in clinical settings with limited resources, use clinical judgment or scores combined with complete blood count (CBC) and blood cultures to detect neonatal sepsis.

Components of the CBC that can become abnormal in sepsis has a positive predictive 
value (PPV) which can be as low as $11 \%$.This can be explained by the inter-observer variability in immature \& mature neutrophil identification, factors other than sepsis that cause abnormalities of the $\mathrm{CBC}$, and timing of the CBC that is often normal at the time of initial evaluation but abnormal a few hours later. Okascharoenet al. devised and tested a scoring system for the diagnosis of LOS in preterm infants composed of the following five clinical indicators: hypotension, hypothermia, hyperthermia, respiratory insufficiency, and umbilical venous catheters between 1 and 7 days or more than 7 days; and the two following haematological parameters: immature neutrophil count more than $1 \%$ and platelet count less than $150000 / \mathrm{ml} 3$. The clinical score had an acceptable predictive performance [PPV 43\%, negative predictive value (NPV) 96\%] but was no better than the clinician's estimate of LOS risk. The addition of C-reactive protein (CRP) and micro erythrocyte sedimentation rate (mESR) to a clinical score in detecting LOS had a high sensitivity (95\%) but a low specificity (18\%)[6].

\subsection{Haematological Markers}

- CBC: Leukocytosis $>20000$, leukopenia $<6000$. Studies have shown that predictive value of high WBC count is low and $30 \%$ of the newborns with clinically proven sepsis have normal WBC count. Leukopenia is a more specific indicator of neonatal bacterial sepsis than Leukocytosis [7]. The normal value of neutrophil count differs with postnatal age and is a more sensitive \& specific indicator of bacterial sepsis than the white blood cell (WBC) counts, particularly, if below the normal range than above the normal range.

Similarly, low platelet count is commonly found in newborns with sepsis. Up to $50 \%$ of newborns with sepsis develop thrombocytopenia in later stages. However, thrombocytopenia is a low-sensitive and nonspecific indicator of neonatal sepsis as it noted in many cases of other neonatal disorders.

- I: T ratio: Increase in immature (band forms, metamyelocytes and myleocytes) to total white cell ratio $>0.3 \%$ is $85 \%$ sensitive and specific, particularly for early onset sepsis (EOS). However, elevated $\mathrm{I} / \mathrm{T}$ ratio are observed in many other conditions and their positive predictive value is limited. It should be considered with other sepsis markers.

\section{MICROBIOLOGICAL METHODS :}

Blood culture: It is still considered the gold standard in diagnosing neonatal sepsis. Blood cultures are done for aerobes, anaerobes and fungus. However, anaerobic blood culture is rarely required in paediatric patients. Blood cultures as mentioned earlier have its own limitations. These can be enlisted as:

Long duration required for the report: Blood culture takes at least 24-48 hours to identify the organisms [8].

Fastidious organisms and maternal antibiotic treatment decrease the sensitivity.

Inadequate sample volume (because of difficulty to collect blood in neonate) decreases the sensitivity. Several studies have showed that the isolation rate from blood culture increases with quantity of blood sample submitted [9].

Contamination of blood culture by skin bacteria such as coagulase negative staphylococci (CoNS) can interfere with the diagnosis.Over the years many advances have been made to reduce the time for blood culture and its sensitivity. The older conventional blood culture methods have been replaced now by newer automated continuous blood culture monitoring systems. In these techniques, the culture bottles are monitored and checked by the computers every fixed interval instead of doing it manually. These systems rely on [10]: Detection of increase $\mathrm{CO}_{2}$ by microorganisms (BACTEC FX/9000 BD, NJ, USA)

Colorimetry (BacT/ALERT series, bioMerieus France)

Pressure change associated with release and consumption of gases (Versa TREK, TREK diagnostic system, $\mathrm{OH}, \mathrm{USA}$ )

BACTEC is the most popular blood culture technique used now days. $\mathrm{CO}_{2}$ dissolved in culture media is detected by a sensor. Data is collected about the emission shift of the sensor dye, which is sent to the computer every ten minutes. The software analyses the data and recognizes the increase sustained production of $\mathrm{CO}_{2}$. Bottles matching criteria for significant $\mathrm{CO}_{2}$ increase are signalled for removal and subculture. Advantages of 
automated continuous monitored blood culture technique over the conventional are decreased need of staff for laboratory, decreased contamination rate as monitoring is invasive and decreased time for detection of growth in blood culture as monitoring is continuous. However, subculture is required for pathogen identification and for specific biochemical or another assay.

\section{ACUTE PHASE REACTANTS :}

C - reactive protein (CRP): CRP is an acute phase reactant synthesized by liver. It rises approximately 12 hours after the onset of sepsis and returns to normal with 2-7 days. $>1$ $\mathrm{mg} / \mathrm{dL}$ indicates sepsis. Sensitivity is $85 \%$ and specificity 90\% [11]. CRP has low negative predictive value in EOS. Its non-specific dynamics cannot provide a major role in diagnosis for biomarkers in sepsis. CRP can be increased in other non-infectious conditions such asmaternal fever during labour, prolonged rupture of membranes, fetal distress, shock, intraventricular haemorrhage, perinatal asphyxia, pneumothorax, \& meconium aspiration pneumonitis. The level of CRP response to sepsis was also reported to depend on underlying pathogen. Low rise of CRP is noted in CONS as compared to Staphylococcus aureus, E. Coli \& group B Streptococci.

The combination of CRP $(0.10 \mathrm{mg} / \mathrm{L})$ \& full blood examination (abnormal film and/or immature to total neutrophil ratio $>0.2$ ) and/or gastric aspirate ( $>5$ polymorphs/high power field or potential pathogen on Gram stained smear and/or culture of potential pathogen) has a sensitivity rate of $97 \%$, specificity rate of $61 \%$, negative predictive value of $98 \%$ and probable ratio of 49 for early-onset neonatal sepsis [12], [13].

Procalcitonin (PCT): Procalcitonin, a propeptide of calcitonin is another important acute phase reactant produced by monocytes and hepatocytes which starts to rise 4 hours after exposure to bacterial endotoxin, peaks at 6-8 hours, and remains raised for at least twenty-four hours with a half-life between 2530 hours. $>0.25-2 \mathrm{ng} / \mathrm{L}$ suggests sepsis, $>2 \mathrm{ng} / \mathrm{mL}$ strong suggestion of sepsis. It is preferred investigation of choice in EOS over CRP [12], [14]. Various studies have observed that serum procalcitonin concentrations increase considerably in necrotizing enterocolitis, systemic bacterial infections, and during both early and later onset neonatal sepsis [15]. It is superior to other acute phase proteins, with sensitivity \& specificity rates ranging from $87 \%$ to $100 \%$.

IL-6: It is also considered a nonspecific marker of infection. It is a pro-inflammatory cytokine produced by macrophages, monocytes and mast cells. There is a sharp increase in IL-6 concentration on exposure to bacterial products, which foreshow the rise in CRP. Umbilical cord blood IL-6 has been consistently shown to be a sensitive marker for diagnosing EOS with sensitivity range between $87-100 \%$ \& negative predictive values ranging between 93-100\% [16]. IL-6 has the highest negative predictive value (91\%) \&sensitivity rate (89\%) at the onset of infection when compared with other biochemical markers, including IL1B, CRP, TNF- $\alpha$ \& E-selectin, but sensitivity is decreased at twenty-four \&fourty-eight hours because IL-6 concentrations decrease very rapidly \& become undetectable after twentyfour hours ${ }^{12}$. The combination of measurement of IL-6 (early and sensitive) with CRP (late and specific) in the first fourty-eight hours of presumed septic episodes can improve the sensitivity when compared with either of the marker alone [12].

IL-8: It is a pro-inflammatory cytokine that is mostly produced by macrophages, monocytes \& endothelial cells, with similar kinetics to IL6 [17]. It is produced as a response to different stimuli such as polysaccharide and TNF. IL-8 is known to be a highly specific marker which has sensitivity ranging from $80 \%$ to $91 \%$ and specificity from $76 \%$ to $100 \%$.

Tumor necrosis factor- $\alpha$ (TNF- $\alpha)$ : Another pro-inflammatory cytokine that stimulates IL-6 production and has a wide spectrum of biological actions on many types of target cell, both immune and non-immune. Newborns developing EOS are usually born with higher TNF- $\alpha$ concentrations than normal infants. Amniotic fluid TNF- $\alpha$ is a biological marker for the prediction of early onset neonatal sepsis in patients with preterm labor and intact membranes, and a much better independent predictor of early onset neonatal sepsis than placental histology, amniotic fluid Gram strain and/or culture. Amniotic fluid TNF- $\alpha$ 
concentration $>41 \mathrm{ph} / \mathrm{mL}$ has a sensitivity of $82 \%$ and specificity of $79 \%$ in the prediction of early onset neonatal sepsis [18].

\section{CELL SURFACE MARKERS :}

This technology appears superior to conventional immunological assay methods for localizing the activated marker to a specific cell type. Neutrophil CD11b and CD64 appear to be the promising markers for diagnosis of early and late onset infection. CD11b is a subunit of $\beta 2$ integrin adhesion molecule. Both CD11b and CD64 are normally expressed at a very low concentration on the surface of nonactivated neutrophils. Its expression, however, rises markedly within a few minutes after the inflammatory cells come in association with bacteria and endotoxins. CD64 had the highest sensitivity (97\%), specificity (90\%), and negative predictive value (99\%) as a diagnostic marker for early onset neonatal infection both at the onset of the infection and 24 hours later [19], [20]. Combining CD64 with IL-6 or CRP further enhances the ability to diagnose localized infections and improves the sensitivity and negative predictive value to $100 \%$ [19]. However, diagnostic uses of these cell markers is not yet fully evaluated. Moreover, currently manual immunoassays are used for determination of cell surface markers; automation is highly desirable to implement the methods in routine clinical laboratory.

\section{MOLECULAR DIAGNOSTICS :}

During the past few years there has been quick progress in molecular biology and nucleic acid-based technologies (NAT). Several NAT based diagnostic approaches have been described [21].

Nucleic Acid-Based Diagnostic Technologies (NAT)

Amplified NAT based methods, e.g.: Polymerase chain reaction (PCR)

Non-amplified NAT based methods, e.g.: Fluorescent based in situ hybridization (FISH), Peptide nucleic acid probes (PNA), etc.

Steps in NAT

Amplified based methods:

Extraction of DNA (step 1) -> Amplification (step 2) -> Identification (step 3)

Non-amplified based methods:

Extraction of DNA (step 1) -> identification (step 2)

Amplified NAT based methods
STEP 1: Extraction of DNA from sample:

Definite purification of DNA from the sample is necessary to any further following NAT based assay.

An optimal extraction method should be sensitive, reproducible, cost-effective, fully automated and universal in its capability for selection of bacterial and fungal DNA.

Methods of nucleic acid extraction as per their source can be enumerated as follows [21] :

\section{Methods of Nucleic Acid Extraction}

Nucleic acid extraction from blood culture bottles: Common problem in extraction of DNA from culture bottles is presence of PCR inhibitors such as anticoagulant and anticomplementary agent sodium polyanethole sulfonate [21], [22]. Nucleic acid extraction from whole blood, serum or plasma: Extraction of EDTA treated whole blood samples provides a higher number of possible target bacteria than methods using serum or plasma, thus improving sensitivity [23]. But obstacles in this technique are the presence of PCR inhibitors, cost factors and crosscontamination. Purification of fungal nucleic acids from clinical samples: Purification of DNA from pathogens such as yeasts and molds is more troublesome. Difficulties in these are low sensitivity of many NAT based approaches for detection of fungal DNA because of difficulty in breaking fungal cell wall, low loads of fungal cells in fungemia [21], [24].

STEP 2: Amplification

Most widely used technique for nucleic acid amplification and detection is polymerase chain reaction (PCR). The ability of this method to amplify minute amounts (less than 3 copies) of specific microbial DNA sequences makes it a powerful tool [25].

Five main drawbacks hinder diaqnostic yield of any molecular assay [2]:

Presence of PCR inhibitors in blood sample Presence of contaminating bacteria and fungal DNA in the reagents: Methods for the removal of potential background contamination include long wave UV light gamma irradiation DNAse, restriction endonuclease digestion, ultrafiltration, and low DNA polymerases. However, many of these methods result in a reduced sensitivity in detecting target DNA, with a detection limit range of 103-104 copies/mL, which is not ideal for diagnosing 
sepsis in clinical settings.

Risk of carryover contamination among sample: PCR product can even spread as airborne droplets in areas of sample or reagent preparation. This contaminating DNA can serve as a template for further amplification resulting in false positive test. Assay may find residual DNA of pathogenic microorganism after proper analysis and it does not make clarify whether this shows any presence of viable organism or amplified DNA from nonviable organism. Interference of high levels of human DNA with extraction and amplification of less abundant bacterial or fungal DNA.

\section{PCR Technique}

Amplification by PCR techniques includes the following steps [20] :

Nucleic acid extraction

Heat $\left(90-95^{\circ} \mathrm{C}\right)$ is used to separate extracted double stranded DNA into single stranded.

Sample then cooled to $55^{\circ} \mathrm{CPrimers}$ designed specifically to flank target nucleic acid sequence adhere to target DNA.

Enzymes polymerase and nucleotidase added to create new DNA fragments complementary to target DNA.

Entire sequence is repeated several times so that after 30 cycles millions of copies of original target DNA are created.

\section{STEP 3: Identification of Pathogen}

Several strategies for the detection of bacterial and fungal DNA have been described. Identification of pathogen from positive blood culture does not overcome any technical and sensitivity issues observed with blood culture, moreover molecular identification may precede the results obtains by culture methods by only few hours. Of more value will be the identification of bacterial and fungal DNA from blood, plasma or serum samples. Three strategies have been described for identification of pathogen [21] :

Pathogen specific assay: Several molecular targets have been used for specific detection of different pathogens, but their clinical usefulness in diagnosis of sepsis is limited by a large number of pathogens potentially involved. However, these assays may be useful in identification of slow growing or fastidious organism, e.g. brucellosis, Q fever, bartonellosis, etc [26].

Genus specific assay: This allows identification of given group of pathogens without further identification to species level. A condition that could greatly benefit from genus-specific approach is detection of invasive aspergillosis. An increasing body of evidence is demonstrating usefulness of such genus- specific approach for neutropenic patients [27].

Broad range assay: An example is the application of broad-range assays for neonatal sepsis, where the performance of blood cultures is often disappointing with a high number of false positives. According to some authors, for neonatal sepsis, a test with rapid turnaround time with a sensitivity superior to that of blood cultures may be desirable even if there are some problems of specificity, such as with broad-range PCR [12].

Multiplex assay: In multiplex assay, multiple analytes (i.e. biomolecules) are measured in a single cycle within a biological sample. It allows rapid identification of pathogen by using multiple primers in a single PCR.

\section{PCR Based Methods :}

Detection by PCR does not provide the antimicrobial sensitivity pattern of the pathogen. Moreover, amplification of known resistance genes grants fast recognition of bacteria which are resistant to certain drugs for example, methicillin resistance for staphylococcal species. With the function of real time PCR, DNA isolation can be accomplished as less as 20 minutes. Early omission of bacterial infection could help to cut down overuse of antibiotics.It is presumed that ultimately real time PCR joined with DNA Microarray technology will permit not only identification of the organism but also the antimicrobial sensitivity pattern, which is critical to clinical care [21].

Nonamplified NAT Based Methods :

Nonamplification methods for detecting bacteria are also commercially available or are evolving to the point that they can be easily performed in a clinical laboratory. Many of the commercially available non-amplification NATs rely on detection of a specific target by chemiluminescence, colorimetric, or fluorescent signals [21].

Fluorescent in situ hybridization (FISH) 
technique: It involves identifying the organism after hybridization to fluorescence- labelled DNA probes and then visualizing the samples under fluorescent or confocal microscope [10]. Probes usually target $\tau$ RNA gene sequence and detect pathogens within 1-2 hours. Pathogen specific probes are available commercially or they are custom designed for target organism. Family, genus and speciesspecific probes are developed for various organisms.

Peptide nucleic acid probes: In 1991, Neilson et al discovered a DNA analogue called peptide nucleic acid (PNA) [29]. These probes are similar to FISH probes but are synthetic oligomers, where negatively charged sugar phosphate backbone of DNA is replaced with noncharged polyamide or peptide backbone. $^{18,30}$ PNA probes have distinct advantage over DNA probes including the stability of PNA/RNA hybrid due to the uncharged PNA. Also, PNAs enter a bacterial cell more easily because of their relative hydrophobicity. It has been used to differentiate Candida albicans and Candida glabrata and was found to be faster than conventional methods [31].

Molecular diagnostics have the potential to increase the speed and accuracy of bacterial identification in clinical laboratory. However, till date NATs have many limitations like false positivity, cost factor and technical expertise. Definitely these limitations are expected to be solved over time period. Integrated, closed Microsystems will help in contamination prevention and false positivity. As more commercial assays are developed and cost comes down with evolving technology, molecular diagnostics enjoys to have great future in rapid diagnosis of neonatal sepsis.

Nonmolecular Biomarkers. Identification of bacteria and fungi in culture growth using proteomics profiles by Matrix Assisted Laser Desorption Ionization/Mass Spectrometry (MALDI-MS) has been evaluated and proved to be a powerful tool. MALDI-TOF MS represent "Matrix Assisted Laser Desorption Ionization Time of Flight Mass Spectrometer". MALDI is a soft ionization procedure which is used in mass spectrometry, that allows the analysis of biomolecules (biopolymers like DNA, proteins, peptides and sugars) and large organic molecules (such as polymers, dendrimers and other macromolecules), which tend to be fragile and fragment when ionized by more conventional ionization methods [33]. By analysing the patterns of fragments it is possible to deduce the structure of the molecule. This principle is used in identification of the microorganism. Time of flight (TOF) is the name of mass spectrometer. ${ }^{23}$ It can provide an identification of a microorganism's genus and species in just a few minutes [34-37]. This technique allows significant time savings with respect to traditional identification methods. MALDITOF mass spectrometry is not used for antibiotic susceptibility testing and an existing method should be used. The technology is particularly well-suited to large laboratories.

The microbe in question is smeared straight on to the sample target and superimposed with matrix. Matrix is the crystallized low molecular weight molecules. The sample with matrix is then irradiated through laser. Matrix absorbs the laser light, vaporizes with the sample and in the process gets charged (ionized). These generated ions display series of lines corresponding to different fragments from the sample. These patterns of fragments are analyzed by dedicated software and compared with stored profiles. Species diagnosis by this procedure is much faster, more accurate and cheaper than other procedures based on immunological or biochemical tests [36].Various studies have proved that MALDI-TOF MS gives 99\% accurate and reliable results even when various culture methods are used and it is especially very useful for fastidious, slow growing organisms like anaerobes, fungi and mycobacterium. It can also identify bacteria in low abundance in mixed flora [37-38].

Taking into consideration the fast and robust identification by MALDI-TOF MS, it can become a new standard for identification of organism in high end laboratories and replace the conventional method of bacterial identification.

In near future [37] but the limitations of MALDI-TOF MS are: it can identify the organism only from positive culture and not from clinical samples and it does not give the antibiotic sensitivity. So, although it has accuracy in identification or organisms, it decreases only the time frame required for that 
by conventional methods.

\section{ANTIMICROBIAL MANAGEMENT FOR NEONATAL SEPSIS :}

The antibiotics that are commonly used to treatneonatal sepsis are ampicillin, gentamicin, cefotaxime, vancomycin, erythromycin, and piperacillin. The selection of antibiotics should be based on the organisms associated with sepsis, the sensitivities of the pathogen, and the common nosocomial infections. Viral infections, such as herpes and fungal infections, can masquerade as bacterial infections[7].

\section{Antibiotics}

Empiric antimicrobial treatment must be complete and should include all the pathogens in relation of the clinical setting. Neonatal dose for antibiotics is based on various parameters (eg, postmenstrual age [PMA], postnatal age, and weight).

\section{Ampicillin}

Ampicillin is a beta-lactam antibiotic that is bactericidal, and it includes group B Streptococcus (GBS), Listeria, nonpenicillinase-producing Staphylococcus, strains of Haemophilus influenzae, and meningococci. Some publications recommend ampicillin (in combination with gentamicin) as first-line therapy for suspected sepsis in the newborn [8].

\section{Gentamicin}

Gentamicin is an aminoglycoside that is bactericidal forgram-negative organisms, like Escherichia coli and Pseudomonas, Proteus, and Serratia species. It is useful when combined with ampicillin for GBS and Enterococcus. Some publications also recommend gentamicin(combination with ampicillin) as the first-line therapy for sepsis in the newborn.

\section{Cefotaxime}

Cefotaxime is a third-generation cephalosporin which has an excellent in vitro activity against GBS and E coli and other gram-negative enteric bacilli. Therapeutic concentrations can be attained in serum and cerebrospinal fluid (CSF). Concern exists that emergence of drugresistant gram-negative bacteria may occur more rapidly with cefotaxime coverage than with traditional penicillin and aminoglycoside coverage[9].

\section{Vancomycin}

Vancomycin is a bactericidal agent that is beneficial against aerobic and anaerobic grampositive cocci and bacilli. It is very much important in the treatment of methicillinresistant Staphylococcus aureus (MRSA) and it is advised when coagulase-negative staphylococcal sepsis is found out. Moreover, treatment with rifampin, gentamicin, or cephalothin may be needed in cases of endocarditis or CSF shunt infection with coagulase-negative staphylococci.

\section{Chloramphenicol}

Chloramphenicol is known to be beneficial in the treatment of highly resistant bacterial meningitis. It inhibits protein synthesis by binding reversibly to $50 \mathrm{~S}$ ribosomal subunits of susceptible organisms, which, in turn, prevents amino acids from being transferred to growing peptide chains[10].

\section{Oxacillin}

Oxacillin is a bactericidal antibiotic that has a property to inhibit cell wall synthesis. It is used for the treatment of infections that is caused by penicillinase-producing staphylococci. It can be given as the first line therapy when staphylococcal infection is suspected.

\section{Piperacillin}

Piperacillin is an acyl ampicillin which has exceptional activity against Pseudomonas aeruginosa. It is also effective against Klebsiellapneumoniae, Proteus mirabilis, B fragilis, Serratiamarcescens, and many strains of Enterobacter. It is most often given in combination with the beta-lactamase inhibitor tazobactam[11].

\section{Erythromycin base}

Erythromycin is a macrolide antimicrobial agent that is primarily bacteriostatic and is active against most gram-positive bacteria, such as Neisseria species, Mycoplasma pneumoniae, Ureaplasmaurealyticum, and Chlamydia trachomatis. It is not well concentrated in the CSF. 


\section{TRIMETHOPRIM}

\section{SULPHAMETHOXAZOLE :}

Trimethoprim-sulfamethoxazole is known to be useful in the treatment of highly resistant bacterial meningitis. Trimethoprimsulfamethoxazole inhibits bacterial growth by inhibition of the synthesis of dihydrofolic acid. Trimethoprim-sulfamethoxazole should not be used if hyperbilirubinemia and kernicterus are of concern in the newborn[12].

\section{Antivirals}

A viral infection, from herpes simplex virus (HSV), may pretense as bacterial sepsis. At the onset of the infection, treatment must be initiated promptly to effectively inhibit the replicating virus[13].

\section{Acyclovir}

Acyclovir is prescribed in cases of mucosal, cutaneous, and systemic HSV-1 and HSV-2 infections.

\section{Zidovudine}

Zidovudine, a thymidine analogue inhibiting viral replication is administered in cases of HIV infection.

\section{Antifungals}

Fungal infections maybe mistaken for bacterial ones, or they may occur as opportunistic infections at the end of prolonged antibacterial treatment. They act by inducing changes in RNA and DNA metabolism or increasing intracellular concentration of peroxide, which is toxic to the fungal cell.

\section{FLUCONAZOLE :}

Fluconazole is the drug of choice for treatment of esophageal, vaginal and oropharyngeal candidiasis. It is also used forsystemiccandidal infections and cryptococcal meningitis. Fluconazole has fungistatic activity. It is a synthetic oral antifungal (broad-spectrum bistriazole) that selectively inhibits fungal CYP450 and sterol C-14 alpha-demethylation, which prevents conversion of lanosterol to ergosterol, thereby disrupting cellular membranes.

\section{Amphotericin B}

Amphotericin B is used to treat severe systemic infections and meningitis caused by susceptible fungi, such as Candida and Aspergillus species, Histoplasmacapsulatum, and Cryptococcus neoformans. This agent is a polyene produced by a strain of Streptomyces nodosus; it can be fungistatic or fungicidal. Amphotericin B binds to sterols, such as ergosterol, in the fungal cell membrane, causing intracellular components to leak and subsequent fungal cell death[16].

Table 1 :List of Organisms

\begin{tabular}{|c|c|c|}
\hline Organism & Antibiotic & $\begin{array}{l}\text { Bactere } \\
\text { mia }\end{array}$ \\
\hline GBS & $\begin{array}{l}\text { Ampicillin or } \\
\text { pencillin G }\end{array}$ & 10 days \\
\hline E.coli & $\begin{array}{l}\text { Cefotaxime } \\
\text { ampicillin } \\
\text { gentamicin }\end{array}$ & $\begin{array}{l}10 \text { to } 14 \\
\text { days }\end{array}$ \\
\hline CONS & Vancomycin & 7 days \\
\hline $\begin{array}{l}\text { Klebsiella, } \\
\text { Serratia }\end{array}$ & $\begin{array}{l}\text { Cefotaxime } \\
\text { Meropenem and } \\
\text { gentamicin }\end{array}$ & $\begin{array}{l}10 \text { to } 14 \\
\text { days }\end{array}$ \\
\hline $\begin{array}{l}\text { Enterobacter, } \\
\text { Citrobacter }\end{array}$ & $\begin{array}{lr}\text { Cefepime } & \text { or } \\
\text { Meropenem and } \\
\text { gentamicin }\end{array}$ & $\begin{array}{l}10 \text { to } 14 \\
\text { days }\end{array}$ \\
\hline Enterococcus & $\begin{array}{l}\text { Ampicillin or } \\
\text { Vancomycin and } \\
\text { gentamicin }\end{array}$ & 10 days \\
\hline Listeria & $\begin{array}{l}\text { Ampicillin and } \\
\text { gentamicin }\end{array}$ & $\begin{array}{l}10 \text { to } 14 \\
\text { days }\end{array}$ \\
\hline Pseudomonas & $\begin{array}{lr}\text { Ceftazidime } & \text { or } \\
\text { piperacillin/tazob } \\
\text { actum and } \\
\text { gentamicin } \\
\text { tobramycin }\end{array}$ & 14 days \\
\hline MRSA & Vancomycin & $\begin{array}{l}10 \text { to } 14 \\
\text { days }\end{array}$ \\
\hline $\begin{array}{l}\text { Staphylococcu } \\
\text { s aureus }\end{array}$ & Nafcillin & $\begin{array}{l}10 \text { to } 14 \\
\text { days }\end{array}$ \\
\hline
\end{tabular}

\subsection{Future expected status of diagnosis and} treatment of neonatal sepsis :

The diagnosis and treatment of neonatal sepsis will always be challenging and complex and dynamic due to resistance patterns and newer organisms and newer antibiotics.

\subsection{Research gap :}

Many faster and newer modalities of diagnosis and treatment of neonatal sepsis need tobe developed. Research agendas include diagnostic techniques, upgradation, antibiotic stewardship, and formulation and discovery of newer antibiotic molecules.

\section{CONCLUSION\& IMPLICATIONS OF RESEARCH AGENDA :}

There is a lot of scope and requirement for research in neonatal sepsis diagnostics and treatment. Currently we do not have any 
method which is rapid, $100 \%$ sensitive and specific for the diagnosis of neonatal sepsis. However, considering the evolving technology and milestone achievement in molecular and nonmolecular methods, such technique may be available in future. But, right now, to decrease morbidity and mortality from neonatal sepsis we have a long way to go to find a method which is rapid, accurate and nearly $100 \%$ sensitive and specific and due to antimicrobial resistance, the right approach to using the best antibiotic to prevent morbidity and mortality, without increasing drug resistance.

\section{REFERENCES :}

[1] Alonso Zea-Vera and Theresa J.Ochoaetal. Challenges in the diagnosis and management of neonatal sepsis. Journal of Tropical paediatrics;2015,61,1-13.

[2] Shamim A.Qazi and Barbara J Stolletal. Neonatal sepsis A major public health challenge.Thepediatric Infectious Journal; Vol 28,January 28.2009.

[3] Theresa J.etal.Diagnosis and management of neonatal sepsis. Journal ofTropical paediatrics;2015.

[4] Meem M, Modak JK, Mortuza R, Morshed M, Islam MS, Saha SK. Biomarkers for diagnosis of neonatal infections: a systematic analysis of their potential as a point-of-care diagnostics. J Glob Health. 2011 Dec. 1 (2):201-9.

[5] Altunhan H, Annagur A, Ors R, Mehmetoglu I. Procalcitonin measurement at 24 hours of age may be helpful in the prompt diagnosis of early-onset neonatal sepsis. Int $J$ Infect Dis. 2011 Dec. 15 (12):e854-8.

[6] Sharma D, Farahbakhsh N, Shastri S, Sharma P. Biomarkers for diagnosis of neonatal sepsis: a literature review. $J$ MaternFetal Neonatal Med. 2018 Jun. 31 (12):1646-59.

[7] Philip AG, Hewitt JR, Early diagnosis of neonatal sepsis. Pediatrics1980;65:1036-1041.

[8] Beekman SE, Diekema DJ, Chaplin KC, Doern GV. Effects of rapid detection of bloodstream infections on length of hospitalization and hospital charges. $J$ ClinMicrobiol2003;41:3119-3125.

[9] Hall MM, Ilstrup DM, Washington JA.
Effect of volume of blood cultured on detection of bacteremia. $J$ ClinMicrobiol1976;3:643-645.

[10] Venkatesh M, Flores A, Luna RA, Versalovic J. Molecular microbiological methods in the diagnosis of neonatal sepsis. Expert Rev Anti Infect Ther2010;8:1037-1048.

[11] Fowlie PW, Schmidt B. Diagnostic tests for bacterial infection from birth to 90 days - a systematic review. Arch Dis Child Fetal Neonatal Ed 1998;78:F92-98.

[12] Mishra UK, Jacobs SE, Doyle LW, Garland SM. Newer approaches to the diagnosis of early onset neonatal sepsis. Arch of Dis Child Fetal Neonatal Ed2006;91:F208212.

[13] Garland SM, Bowman ED, Reappraisal of C-reactive protein as a screening tool for neonatal sepis. Pathology 2003;35:240-243.

[14] Dandona P, Nix D, Wilson MF, et al. Procalcitonin increase after endotoxin injection in normal subjects. $J$ ClinEndocrinolMetab1994;79:1605-1608.

[15] Guibordenche J, Bedu A, Petzol I, et al. Biochemical markers of neonatal sepsis: value of procalcitonin in the emergency setting. Ann ClinBiochem2002;39(Pt2):130-135.

[16] Smulian JC, Vintzileos AM, Lal YL, Santiago J, Shen-Schwarz S, Campbell WA. Maternal chorioamnionitis and umbilical vein interleukin-6 levels for identifying early neonatal sepsis. $J$ MaternFetal Med 1999;8:88-94.

[17] Baggiolini M, Walz A, Kunkel SL. Neutrophil-activating peptide -1/interleukin 8, a novel cytokine that activates neutrophils. $J$ Clin Invest 1989;84:1045-1049.

[18] Kowalik K, Czeszynska MB, Celewicz Z. Evaluation of diagnostic usefulness of the cord blood TNF-alpha levels as a marker of early onset neonatal infection. Genikol Pol 2003;74:439-445.

[19] Ng PC, Li K, Wong RP, Chui KM, Wong E, Fok TF. Neutrophil CD64 expression: a sensitive diagnostic marker for late-onset nosocomial infection in very low birthweight infants. Pediatr Res 2002;51:296-303.

[20] Bhatia BD, Basu S. Newer diagnostic 
tests for bacterial diseases. Indian $J$ Pediatr2007;74:673:677.

[21] Mancini N, Carletti S, Ghidoli N, Cichero $\mathrm{P}$, Burioni R, Clementi $\mathrm{M}$. The era of molecular and other non-culture-based methods in diagnosis of sepsis. ClinMicrobiol Rev 2010;23:235-251.

[22] Fredriks DN, Belmain DA. Improved amplification of microbial DNA from blood cultures by removal of the PCB inhibitor sodium polyanetholesulfonate. $J$ Clinical Microbiol1998;36:2810-2816.

[23] Ohlin A, Backman A, Bjorkvist M, Molling P, Lustrand M, Schollin I. Real time PCR of the $16 S-\tau$ RNA gene in the diagnosis of neonatal bacteraemia.

ActaPaediatr2008;97:1376-1380.

[24] Lzffler J, Hebart H, Schumacher U, Reltze H, Einsele H. Comparison of different methods of extraction of DNA of fungal pathogens from cultures and blood. J Clinical Microbiol1997;35:3311-3312.

[25] Shang S, Chen Z, Yu X. Detection of bacterial DNA by PCR and reverse hybridization in the $165 \tau$ RNA gene with particular reference to neonatal septicemia. ActaPaediatr2001;90:179-183.

[26] Fenollar R, Raoult D. Molecular diagnosis of bloodstream infections caused by non-cultivable bacteria. Int $J$ Antimicrob Agents 2007;30:S7-15.

[27] Farell IJ, Doyle LI, Addison RM, Reller LB, Hall GS, Procop GW. Broad range (Pan) Salmonella and Salmonella serotype Typhispecific Real time PCR Assays Potential Tools for the Clinical Microbiologist. Am J ClinPathol2005;123:339-345.

[28] Valasek MA, Bepa Jl. The power of real time PCB. AdvPhysiolEduc2005;29:151-159.

[29] Neilsen PE, Egholm M, Berg RH, Buchardt O. Sequence-selective recognition of DNA by strand displacement with a thyminesubstituted polyamide. Science 1991;254(5037):1497-1500.

[30] Wang J, Palecek E, Neilsen PE, et al. Peptide nucleic acid probes for sequencespecific DNA biosensors. $J \quad A m$ ChemSoc1996;118:7667-7670.
[31] Pellestor E, Paulasova P, Hamamah S. Pepetide Nucleic Acids (PNA) as diagnostic devices for genetic and cytogenetic analysis. Curr Pharm Des 2008;14:2439-2444.

[32] Seng P, Drancourt M, Gouriet E, et al. Ongoing revolution in bacteriology: routine identification of bacteria by matrix-assisted laser desorption ionization time-of-flight mass spectrometry. Clin Infect Dis 2009;49:543551.

[33] Aptfel JA, Chakel JA, Hancock WS, Lichtenwalter $\mathrm{K}$. Integrated nucleic acid analysis system for MALDI-TOF MS. U.S. Patent 1998;5:716-825.

[34] Claydon MA, Davey SN, Edwards-Jones $\mathrm{V}$, Gordon DB. The rapid identification of intact microorganisms using mass spectrometry. Nat Biotechnol1996;14:15841586.

[35] Bizzini A, Durussel C, Bille J, Greub G, Prod'hom. Performance of matrix-assisted laser desorption ionization-time of flight mass spectrometry for identification of bacterial strains routinely isolated in a clinical microbiology laboratory. $J$ ClinMicrobiol2010;48:1549-1554.

[36] Hseih SY, Tseng CL, Lee YS, et al. Highly efficient classification and identification of human pathogenic bacteria by MALDI-TOF MS. Mol Cell Proteomics 2008;7:448-456.

[37] Van Veen SQ, Claas EC, Kuljper EJ. High-throughput identification of bacteria and yeast by matrix-assisted laser desorption ionization-time of flight mass spectrometry in conventional medical microbiological laboratories. J ClinMicrobiol2010;48:900-907

[38] Carbonnelle E, Mesquita C, Bille E, et al. MALDI-TOF mass spectrometry tools for bacterial identification in clinical microbiological laboratory. 